\title{
PERCURSOS E DISPUTAS DE SENTIDOS E DISCURSIVIDADES NA AMAZÔNIA: A COMUNIDADE DO MACURANY (PARINTINS/AM)
}

\author{
BACKGROUNDS AND STRUGGLES OF MEANINGS AND \\ DISCURSIVITIES IN AMAZONIA: MACURANY VILLAGE \\ (PARINTINS, AMAZON STATE, BRAZIL)
}

\author{
Luiz Carlos Martins de Souza ${ }^{1}$ e Almiro Lima da Silva ${ }^{2}$
}

\begin{abstract}
RESUMO: Neste texto elencamos alguns dos percursos e disputas de sentidos e de discursividades recorrentes na Amazônia, em relação e contraste com a vida da comunidade ribeirinha do Macurany (Parintins/Amazonas). Para isso, nos baseamos em algumas obras e interpretações sobre a história da região, sobre comunidades ribeirinhas e indígenas, de modo a avaliarmos e relacionarmos, pela perspectiva materialista de Análise de Discurso, tais interpretações à realidade dessa comunidade ribeirinha de origem indígena, em Parintins, cidade atravessada pelas contradições das formações sociais amazônidas. Assim, percebemos a recorrência das discursividades instaladas e convocadas com a colonização, o que nos indica que precisamos de mais obras artísticas, escolares, acadêmicas e jornalísticas para expormos e dirimirmos os problemas e os efeitos catastróficos da violência simbólica, moral, política, social, econômica e física, causados por essas discursividades.
\end{abstract}

PALAVRAS-CHAVE: identidades amazônicas; Análise de Discurso; Parintins-Amazonas; ribeirinho

\begin{abstract}
In this text we consider some of the journeys and recurring struggles over meanings and discoursivities in Amazonia, via a study focused on the life of the Macurany riverside community in Parintins, Amazonas state, Brazil. Parintins forms a strong case study site as the city provides an intersection of the contradictions of Amazonian social formations. Accordingly, we used studies and interpretations of regional history, and of riverside and indigenous communities, to evaluate and relate, through the materialistic perspective of Discourse Analysis, these interpretations in contrast with the reality of this riverside community of indigenous origin. We found continuing resonances of the discursivities originally installed during colonization. Such a situation calls for increased investment in artistic works and, school- and academic- and journalism-based activities to analyse and clarify, and also help resolve the problems and debilitating effects of the symbolic, moral, political, social, economic and physical violence caused by those discursivities.
\end{abstract}

KEYWORDS: Amazonian identity; Discourse Analysis; Parintins-Amazonas; riverside community

\footnotetext{
${ }^{1}$ Realizador em audiovisual, pesquisador e professor da área de estudos do discurso e da linguagem verbal e audiovisual na Faculdade de Letras da Universidade Federal do Amazonas, com pós-doutorado em Linguística pela UFRJ.

${ }^{2}$ Oriundo da comunidade do Macurany, é mestre em Letras pela Universidade Federal do Amazonas - UFAM e professor da Secretaria de Estado de Educação do Amazonas - SEDUC/AM.
} 


\section{A formação histórico-social de Parintins e da comunidade do Macurany}

Na comunidade do Macurany moram aproximadamente 2.000 pessoas. Ela se localiza na área sul da Ilha Tupinambarana, onde fica a cidade de Parintins-AM, cuja população total atual é de 114.273 habitantes, conforme estimativa do IBGE em 2019. A comunidade fica à distância de $8 \mathrm{~km}$ do centro urbano do município, com acesso por estrada e é para onde a urbe de Parintins está se expandindo. $\mathrm{O}$ fato de localizar-se nas proximidades da cidade, faz com que a história do Macurany seja não só envolvida nas lutas e disputas da história da própria cidade de Parintins, mas também seja atingida pelas mudanças no interior da Amazônia que impactam o planeta: a complexidade do universo urbano globalizado se confronta com o universo ribeirinho e indígena dentro de processos discursivos que os constituem. Nosso objetivo aqui é elencar alguns dos percursos e disputas de sentidos recorrentes na Amazônia, a partir da existência histórica da Comunidade do Macurany ${ }^{3}$. Para isso, pensando discursivamente com as categorias de contradição, de equivocidade, de disputa de sentidos e de interpretações, retomamos uma revisão bibliográfica sobre a região e relacionamos algumas interpretações do que dizem alguns pensadores com a realidade de uma comunidade ribeirinha de origem indígena, numa cidade atravessada pelas contradições das formações sociais amazônidas. Para análises mais acuradas com diferentes corpora que circulam na região, citamos adiante alguns trabalhos que se ocupam mais detidamente disso, já que o espaço e nosso objetivo não nos permitem retomar o que já está publicado em outros textos.

O município de Parintins fica na sub-região Baixo Amazonas, sua sede municipal está situada à margem direita do rio Amazonas, distante $369 \mathrm{~km}$ em linha reta de Manaus e $420 \mathrm{~km}$ por via fluvial (SILVA, 2009), distância aproximadamente equivalente entre Porto Alegre (RS) e Florianópolis (SC). Por estar nas proximidades da linha do Equador, Parintins possui um clima quente e úmido, uma grande bacia hidrográfica, uma grande floresta e uma rica biodiversidade.

Conforme Saunier (2003), a ilha de Parintins, antes da chegada dos colonizadores, foi habitada por diferentes povos indígenas, cujos vestígios são encontrados em vários locais: áreas de terra preta (sítios arqueológicos), cerâmicas indígenas e castanhais. Normalmente esses sítios arqueológicos são detectados, mas ficam abandonados ou são soterrados pelo avanço urbano. Essa violência simbólica com o próprio passado, desprezando-o ou ignorando-o, tem

\footnotetext{
${ }^{3}$ Esse trabalho é em grande parte baseado na pesquisa do prof. MSc. Almiro Lima da Silva, orientado pelo dr. Luiz Carlos Martins de Souza. Essa pesquisa resultou na dissertação de mestrado "A memória e o presente da comunidade do Macurany, em Parintins/AM: análise discursiva”, de 2018, financiada pela FAPEAM, no PPGL/FLET, da Universidade Federal do Amazonas (UFAM).
} 
fundamento nas discursividades que constituem o indígena e especialmente a Amazônia, como mais adiante esclareceremos.

Vivemos em uma região cuja complexidade envolve não só questões de ordem natural, mas também de ordem cultural, social, econômica e política, decorrentes de processos históricos cujos registros se limitam ao que se desenrolou desde a chegada dos colonizadores europeus nestas terras (BATISTA, 2007). Essa complexidade envolve diferentes instâncias de disputas de sentido e de constituição de sujeitos (PÊCHEUX, 1988; ORLANDI, 1999; MARTINS DE SOUZA, 2012).

É uma região, desde o século XVI, segundo Tocantins (1983), muito cobiçada e sobre a qual foram criados mitos e imagens distorcidas, disputas de interpretação que nos interessam teoricamente. Conforme o autor, expedições espanholas saíram do Peru à procura de novas fontes de especiarias, especificamente à procura do País da Canela, um lugar onde haveria tanta canela, que os indígenas fariam delas suas armas. Era, no entanto, uma antevisão idealizada das paisagens do vale amazônico. Não encontrando o tão imaginado país, a expedição comandada pelo espanhol Francisco Orellana, descendo o rio Amazonas, relatou terem encontrado o País das Amazonas (alusão à mitologia grega), onde mulheres guerreiras cortavam um dos seios para melhor manejar os arcos, eram hábeis na montaria de cavalos, lutavam bravamente e viviam sem homens, entrando em contato com eles somente durante um determinado tempo, período em que engravidavam. Das crianças geradas, somente as de sexo feminino eram criadas por elas. Aí, tem-se a lenda da qual se originou o nome Amazonas e sua derivação, Amazônia. Para Tocantins (1983), os viajantes europeus, de modo geral, sempre tiveram o espírito sensível para a criação ou recriação de mitos e lendas. Para nós, interessa pensar nos modos como os primeiros europeus nas Américas precisavam referenciar o que não tinha nomeação em suas línguas e o que não tinha memória em seu imaginário. Além disso, em diferentes materialidades significantes (LAGAZZI, 2011), a ambiguidade entre essa frustração de expectativas e a ânsia pelas riquezas encontradas na região sustenta duas formas de afetos que permeiam as formações discursivas (PÊCHEUX, 1988) predominantes, em disputa na Amazônia e sobre a Amazônia, que constituem os sujeitos e as obras que, com ela, se relacionam: o amor ou o ódio, o deslumbramento ou a repulsa, a sedução pelo seu mistério ou o pavor de sua monstruosidade, a vontade de conhecê-la ou o ímpeto de dominá-la, explorá-la e destruí-la; penetrá-la respeitosa e delicadamente ou estuprá-la violentamente, como mostram as análises empreendidas por Martins de Souza (2008, 2019), Lima da Silva (2018), Rodrigues de Araujo (2018).

De acordo com Saunier (2003), a primeira informação registrada sobre Parintins é datada de 23 de junho de 1542 e está presente no diário de viagem de Francisco Orellana e 
Gaspar de Carvajal, de quando passavam pelo rio Amazonas na já referida expedição, que partiu do Peru até sair no Atlântico. Ao passarem pelo povoado indígena (hoje Parintins), deram-lhe o nome de "Las Picotas". A nomeação dos lugares e dos espaços não é desvinculada de processos discursivos (MARTINS DE SOUZA, 2000). Vemos que, de um lado, os colonizadores conseguiram nos impor sua língua e o nome grego da região e do Estado. Entretanto, na disputa de sentidos e de referenciações, permanece a contradição com termos de línguas indígenas, como "Parintins" e "Macurany". Isso se traduz na nomeação não só de lugares, mas também dos alimentos da região, nos frutos e produtos que só exclusivamente nela se encontram e em alguns termos do léxico usado no nosso cotidiano. Há contraditoriamente uma negação das origens milenares indígenas e um orgulho dos sabores exóticos da alimentação e da culinária amazônica, mantendo termos de diferentes línguas da região, não só na nomeação das localidades, mas também nos peixes (tambaqui, tucunaré, pirarucu, piranha), nos frutos (cupuaçu, tucumã, umari, biribá, açai, buriti), nos pratos (tacacá, piracui, tapioca), nas bebidas e ingredientes (guaraná, tucupi, caxiri) dentre outros.

\section{A colonização da Amazônia: as almas e o corpos em disputa}

No que diz respeito à Amazônia brasileira, na interpretação de Tocantins (1983), o ato decisivo da empresa colonial lusitana para a posse e integração das duas colônias que se tornaram o Brasil foi a expedição de Pedro Teixeira, que partiu de Cametá em 1637, subindo o rio Amazonas até Quito, retornando a Belém, Estado do Maranhão e Grão-Pará, em 1639, efetivando o domínio português por lugares antes não palmilhados por esses colonizadores. É preciso ressaltar que essa discrepância entre duas colônias nas Américas, do Brasil e do GrãoPará e Maranhão, produz uma cisão até hoje incontornável, em que o senso comum, as oportunidades desiguais, os espaços oferecidos e as políticas públicas do país abandonam, ignoram, silenciam e desqualificam os povos e as produções simbólicas amazônidas, impedindo-nos de nos exprimirmos e usufruirmos de nossas riquezas e do que somos. $\mathrm{O}$ abandono, a sensação de abandono e a rejeição estruturam nossa realidade simbólica e material e constituem nossa subjetividade (MARTINS DE SOUZA, 2000, op. cit., 2019), (LIMA DA SILVA, 2018).

Assim, segundo esses autores, 137 anos depois de começarem a colonizar a costa brasileira, os portugueses iniciaram o processo de colonização da Amazônia, primeiramente através da colonização religiosa. Segundo Tocantins (op.cit.), urgia que se chamassem os indígenas para o convívio "civilizado”, para utilizá-los nas lidas nas lavouras e na defesa da 
terra. Mas, seria esse mesmo o modo de convencê-los, domesticá-los e escravizá-los? Portugal reconheceu oficialmente, pela Carta Régia de 1693, o serviço de catequese empreendido pelos religiosos. Esse trabalho foi realizado pelos jesuítas e, além deles, pela ordem dos piedosos, dos carmelitas, dos franciscanos, dos capuchinhos e dos mercedários. Este serviço foi muito importante para Portugal na medida em que subordinava os indígenas às colônias, mas, com o tempo, gerou muitos conflitos entre os colonizadores (donos de lavouras, de fazendas etc.) e os missionários. Segundo Wagley (1988), no seu livro Uma Comunidade Amazônica, era uma guerra entre os caçadores de escravos brasileiros, que queriam o corpo dos indígenas para o trabalho forçado, e os jesuítas (e outros missionários), que queriam a suas almas. Luta esta em que os indígenas brasileiros estavam destinados a perder ambos, corpos e almas. Pombal assumiu o governo português em meados do século XVIII e expulsou os jesuítas do Brasil, submetendo os indígenas ao trabalho forçado e impondo-lhes o ensino da Língua Portuguesa em substituição à Língua Geral, o Nheengatu, uma modificação e generalização das diversas línguas do tronco Tupi, cuja gramática e parte do léxico se embasa no português e no espanhol. Foi essa a língua empregada pelos missionários no ensino catequético dos indígenas convertidos e ainda hoje é falada em algumas regiões do Amazonas e do Pará. Isso nos mostra que parte dos historiadores, trabalhando com uma interpretação unilateral dos fatos, ignoram as disputas e contradições de sentidos. Missionários buscavam um modo de assujeitamento pela religião. Colonizadores, pela escravidão, o assujeitamento dos corpos, pelo trabalho, pela língua, pelo disciplinamento dos horários, dos hábitos e das pulsões. É difícil pensar também nas imensas extensões de terra da Amazônia, caso de Parintins, como isso se processaria uniformemente. Há razões para supormos que em determinadas áreas, mais cobiçadas e mais acessíveis, o funcionamento dessa dicotomia aconteceu de um modo diferente de áreas mais distantes, isoladas e com acesso mais difícil. Essa relação de forças entre o desejo de produtividade, o desejo de salvação e a catequização, o silenciamento linguageiro, motivando o projeto colonial, e o contraponto da insubmissão parcial dos povos indígenas ao estilo de vida nos padrões europeus e católicos, constitui ainda hoje a sexualidade e a temporalidade na Amazônia, o modo assombrado como europeus e brasileiros de outras regiões constatam a liberdade e a ousadia feminina na sedução (MARTINS DE SOUZA \& FREIRE, 2004; MARTINS DE SOUZA, 2019), e, como constatamos no comportamento de grande parte da população na Amazônia, durante a pandemia de COVID-19, a insubmissão a regras, agendas e cronogramas de autoridades da academia ou do Estado. Nesse momento, no fim de maio de 2020, o Amazonas é o Estado que tem a maior taxa de mortos de COVID-19 por milhão de habitante. Portanto, isso não significa apenas uma resistência à opressão, à dominação, aos poderosos. É sobretudo 
um abrigar-se no desejo do Outro, um desejo mortal, de extinção, de destruição, de assumir para si o destino trágico traçado no processo histórico e em sua visibilidade discursiva e subjetiva (MARTINS DE SOUZA, 2019). A violência simbólica e a violência física preservamse no país e na região, destruindo-nos, devastando-nos.

Conforme Tocantins (1983), devido à vastidão da área sob o domínio da Colônia do Grão-Pará e Maranhão, e havendo exigência de melhor tomar posse da região, especialmente nas bandas do Rio Negro, águas que davam acesso a outros povos sujeitos à política de Portugal, foi então criada a Capitania de São José do Rio Negro, hoje cidade de Manaus, capital do Estado do Amazonas, por meio da Carta Régia de 1755, e que ficou subordinada ao governo da Capitania do Grão-Pará até ser elevada à categoria de Província 95 anos depois.

Saunier (2003) e Bittencourt (1924) fazem referência a acontecimentos históricos dos séculos XVII e XVIII, em Parintins. Mas há divergência entre eles quanto à chegada do primeiro colonizador àquelas terras. Para Saunier (2003), foi o padre alemão João Felipe Bettendorff, em 29 de setembro de 1661, acompanhado de outros missionários, quem primeiro desembarcou na Ilha dos Tupinambaranas e dedicou uma capela a São Miguel, nomeando a localidade de São Miguel dos Tupinambaranas. Esse padre, segundo o autor, era fundador de missões e vilas e havia fundado a missão dos Tapaiu, hoje Santarém, em 1661.

Já para Bittencourt (1924), o primeiro a chegar foi o capitão de milícias José Pedro Cordovil, em 1796, trazendo consigo um grupo de escravos para dedicarem-se à pesca do pirarucu, à plantação de tabaco, cacau, guaraná e maniva. Segundo este autor, Cordovil é quem teria nomeado a Ilha Tupinambarana. Saunier (2003), assim como Reis (1967), afirmam que o núcleo Tupinambarana foi apenas organizado por Cordovil e denunciam que este não se empenhou nos trabalhos da agricultura, como pediam documentos oficiais da Coroa Portuguesa, porém se interessou pelo extrativismo de produtos da floresta e tinha o gênio irrequieto, submetia os indígenas ao trabalho forçado e criou no lugar um ambiente de hostilidades. As práticas de fraudar relatórios, de impor lideranças, de acusar a população amazônida de preguiçosa e indolente, ressoa em diferentes materialidades, como também já demonstramos em outros trabalhos (MARTINS DE SOUZA \& FREIRE, 2004; LIMA DA SILVA, 2018; MARTINS DE SOUZA, 2019). Assim, na Amazônia ainda funciona, nos produtos simbólicos e na produção social da vida, o mesmo processo discursivo que remonta à colonização: o desprezo pela Amazônia, o desprezo pelos indígenas, a mentalidade de colonizado, em que se inferioriza e menospreza o local para se prestigiar o incensado estrangeiro. O festival folclórico de Parintins, como materialidade discursiva e significante, sintomatiza essa contradição: por um lado, o indígena é recriado ao estilo de filmes apaches 
hollywoodianos, por outro, valoriza-se uma interpretação e exaltação regional da vida cabocla e indígena. Isso mudou o modo como o amazonense se representa no caleidoscópio identitário brasileiro, com a internacionalização do festival (e com sua transmissão em rede nacional) a partir do fim dos anos 80 e com a visita de celebridades nacionais e internacionais. Esse outro estrangeiro, que constitui o Grande Outro ideológico em que nos miramos e nos avaliamos, passa a nos olhar com assombro e admiração, e isso nos impacta coletivamente em nossa expressão cultural.

Também, contraditoriamente, a riqueza da floresta, os sabores dos frutos silvestres e aquáticos, exclusivos da região, enlaçam os sujeitos num lugar ambíguo de significação entre a rejeição e exaltação identitária, em que as significações e os textos, como instâncias de formulação, se debatem em seu consequente sentimento de inferioridade coletiva, bipolarizado com a adoração dos sabores, do exotismo, e das imensidões que a natureza impõe no calor, na umidade, nos rios e no verde a perder de vista. Oscilamos entre nos sentirmos minúsculos, sucumbindo ante o poder e a força da natureza, ou dos povos dominadores do planeta, e nos sentirmos heróis numa jornada mítica de embates com deuses poderosos, para construirmos uma civilização num lugar monstruoso, considerado inóspito, quente, labiríntico e enclausurador.

\section{O crescimento de Parintins e o surgimento legal da Comunidade do Macurany}

Segundo Bittencourt (1924), após Cordovil retirar-se dessa localidade, o Capitão Mor do Pará, Conde dos Arcos, elevou Tupinambarana à categoria de Missão, em 1803, sob a denominação de Villa Nova da Rainha, ficando no comando o carmelita Frei José das Chagas. De acordo com Saunier (2003), após sua instalação, em 1853, o novo município ficou constituído por dois distritos: Parintins e Ilha das Cutias. Esses distritos foram divididos em subdistritos e conforme esse autor, o distrito de Parintins foi dividido em "oito subdistritos: Parintins, Macurani, Paraná do Ramos, Uaicurapá, Serra de Parintins, Paraná do Limão, Paraná do Xibuí e Parananema” (SAUNIER, 2003, p. 37).

Aí temos a informação mais antiga sobre a localidade Macurany, que naquela época ficou como um dos subdistritos de Parintins. Isso prova que em 1853 a localidade Macurany já era habitada. Segundo Bittencourt (1924), Villa Bela da Imperatriz foi elevada à categoria de cidade em 30 de outubro de 1880, dessa vez com a denominação de Parintins.

Dadas as informações acima, vemos que desde a chegada dos colonizadores, Parintins foi fortemente influenciada pela Igreja Católica, sem fugir à regra do processo histórico 
brasileiro. Na Amazônia brasileira, o catolicismo se estabeleceu a partir do século XVII e constitui uma das faces fundamentais do processo de colonização da região, pois, através das ações dos missionários jesuítas, carmelitas, franciscanos e outros, os indígenas foram catequizados e aos poucos submetidos aos valores e costumes da cultura europeia, facilitando assim o trabalho dos colonizadores (OLIVEIRA, 2012). Ainda aqui, os autores tratam dos povos colonizados, como se não houvesse resistência, e como se a negociação entre o poder bélico, econômico e simbólico da dominação e o imenso poder de sobrevivência e de adaptação dos povos indígenas não se desse na contradição e no fingir subserviência, acatando alguns elementos para prolongar sua descendência e subsistência na região.

As mudanças urbanas no interior da Amazônia seguem outros centros. Souza (2013) aponta alguns fatores importantes para o aumento do número de habitantes de Parintins, a Ilha Tupinambarana, considerando o recorte temporal que vai desde os tempos coloniais até a década de 1960. De acordo com ela, esses fatores se referem a períodos econômicos vivenciados com destaque no município, afetando seu processo de produção e evolução do perímetro urbano. Entre eles temos:

- a indústria extrativa, em que se extraía da floresta castanha, borracha fina, sernambi, caucho, caferana, cumaru, óleos de andiroba e copaíba, muirapua, manacá, copo, salsa, toras de itaúba, cedro e outras madeiras, pele de animais silvestres, entre outras coisas, e dos rios se extraía principalmente o pirarucu, óleo de tartaruga e óleo de peixe-boi;

- o ciclo do cacau que, trazido para Parintins por Cordovil, em 1796, tornou-se um dos principais produtos do município, atraindo, para o lugar, portugueses, franceses e judeus que viviam em outras localidades, bem como moradores de estados, municípios e vilas vizinhas;

- a pecuária, atividade que possibilitou ao município, a partir do ano de 1917, registrar um rebanho de 19.349 reses da raça zebu, exportado para Manaus e outras localidades, e que foi enfraquecida pelas grandes enchentes e pela escassez de pastagens na terra firme;

- a exploração do pau-rosa, cujas primeiras usinas de destilação do seu óleo essencial começaram a funcionar a partir de 1930, e tal essência, usada em marcas famosas de perfumes franceses, chegou a representar aproximadamente $8 \%$ na pauta de exportações do Estado do Amazonas na década de 1960.

Ainda conforme Souza (2013), concomitante à exploração do pau-rosa, deu-se início ao período da juta, a partir de 1927, quando o governo brasileiro cooperou com o governo japonês para o cultivo da juta em Vila Amazônia, localidade à margem direita do rio Amazonas, na 
confluência com o paraná do Ramos, distante $5,6 \mathrm{~km}$ em linha reta da sede municipal de Parintins. Houve uma importante imigração japonesa para a região. Os trabalhos de cultivo da juta e outras espécies prosperavam, quando, em decorrência da II Guerra Mundial, muitos japoneses foram expulsos do país, uma vez que o Brasil aliou-se a países adversários do Japão na guerra. Mesmo com a saída da maioria dos japoneses da Vila Amazônia, os parintinenses assimilaram a forma de cultivo da juta, que perdurou por pelo menos 50 anos. Ainda hoje muitas famílias, de descendência japonesa, ocupam a cidade de Manaus, de Parintins, de Santarém e de Belém.

Como já dito, esses períodos econômicos, entre outros fatores, contribuíram para a configuração urbana de Parintins até a década de 1960, quando a população do município era de 27.525 habitantes, sendo que a população rural, espalhada nas margens dos rios e igarapés, representava 75\% desse total (SOUZA, 2013).

\section{A presença da Igreja Católica na Comunidade do Macurany: ser ou não ser comunidade}

A discursividade cristã católica afeta muito as formas de organização de comunidades rurais (ribeirinhas) na Amazônia. Em geral elas se organizam espacialmente em torno de uma igreja católica. Isso aconteceu no município de Parintins mais restritamente a partir da década 1960. Em 1955 foi criada a Prelazia de Parintins e em 1961 aconteceu a ordenação do primeiro bispo, Dom Arcângelo Cerqua. A partir desse momento, iniciou-se um trabalho intenso da Igreja Católica em Parintins e nos municípios vizinhos, principalmente com a atuação dos missionários do Pontifício Instituto das Missões Exteriores (PIME) (CERQUA, 1980).

Na década de 1960 foram fundadas várias Comunidades Eclesiais de Base em todos os municípios pertencentes à Prelazia de Parintins, tanto na área urbana quanto na área rural. Segundo Cerqua (1980, p. 311),

\footnotetext{
Um grande número dessas comunidades, principalmente nos últimos anos, nasceu como Congregações Marianas de homens, capela para culto e reuniões formativas. No entanto, em redor de cada capela, não se demoraram a surgir escolas, campo de jogo, cantina comunitária etc., tudo em terreno doado ou vendido à Prelazia; e aos Marianos foram se acompanhando outros movimentos e irmandades, como as Senhoras do Apostolado de Oração, a Cruzada Eucarística Infantil, Clubes de Jovens dentre outros. Várias atividades comunitárias foram se organizando, coordenadas por pessoas responsáveis, qualificadas em cursos administrados pela Prelazia no Centro de Treinamento ou no próprio interior.
}

Tratava-se, pois, da oficialização do catolicismo nestas localidades, uma vez que seus moradores já praticavam um catolicismo popular, não oficial. Os santos católicos eram venerados e homenageados na casa dos próprios moradores, sem o controle eclesiástico. A 
propósito desse tipo de catolicismo na comunidade de Itá, Wagley (1988) registra que nessa comunidade ele era organizado por irmandades, uma forma de associação de devotos de um determinado santo, que não estavam subordinadas à igreja e, por isso, era combatidas pelos padres. Era função dessas irmandades organizar todos os anos a festa do santo ao qual se dedicavam. Na ocasião das festas, havia a mistura do profano e do sagrado. Geralmente, fincavam mastro, faziam procissões por terra e pelos rios e igarapés, rezavam ladainha e outras orações, bem como ofereciam jantar e almoço aos participantes, e vendiam bebidas alcoólicas. Estas festas eram animadas por grupos musicais formados pelos próprios moradores e membros das irmandades, que utilizavam instrumentos tais como tambores, cavaquinhos, violões, violas, matracas, raspadores etc. Para Wagley (1988), essas irmandades constituíam mais do que simples associações de devotos de determinado santo, pois promoviam a organização formal dos povoados rurais onde estavam estabelecidos.

Antes da chegada dos missionários do PIME na localidade Macurany (década de 1950), seus habitantes festejavam São Domingos, Santa Luzia, São Sebastião, Santa Rita e outros santos, da maneira semelhante às irmandades descritas por Wagley (1988). A partir do início da década de 1960, os missionários começaram aí um trabalho de catequese na casa dos moradores, o que culminou com a fundação da Comunidade Eclesial de Base Santa Luzia do Macurany, em 1969 (CERQUA, 1980). Santa Luzia, que se tornou padroeira da localidade, era homenageada e festejada pela família do morador Walter Viana, o qual pagava uma promessa à referida santa por acreditar ter recebido dela a cura de uma doença que acometera sua vista. A implantação oficial da igreja na localidade influenciou diretamente a organização social dos moradores, pois foi instituída uma diretoria eclesial comunitária que, além de cuidar das questões religiosas, tratava também de assuntos de interesse político e social, colocando em grande parte as formas de sociabilidade sob o controle da igreja, como, por exemplo, o time de futebol Atlético Clube Macurany, fundado em 20 de setembro de 1957, pelo morador Antônio Venâncio. Antes sem vínculo com a igreja, passou a chamar-se Atlético Clube Santa Luzia do Macurany e, a partir daí, para tornar-se membro da equipe era necessário frequentar a igreja. É importante destacar a força simbólica e a violência que se perpetua à possibilidade de ser vivo para o Estado ou não, de estar vivo para a Igreja ou não, de ter direito ou não a existir, à sociabilidade, ao pertencimento coletivo. Discursividades de vida e de morte que configuram a Amazônia tal qual ela se mostra, tal qual existe e como definha no planeta.

Apesar de não se permitirem assumir como comunidade, de um ponto de vista sociológico, os moradores já viviam em comunidade antes da chegada da igreja, pois partilhavam a mesma localidade, os mesmos costumes e crenças, os mesmos valores e as 
diferentes formas de sociabilidade, como o trabalho coletivo denominado puxirum, a prática do futebol, a prática do catolicismo popular, a realização de festas dançantes. $\mathrm{O}$ aspecto econômico caracterizava-se pela pesca, agricultura e extrativismo vegetal e animal. Deste modo, o que aconteceu com a chegada da igreja foi uma reorganização e ressignificação dessas práticas a partir de uma perspectiva religiosa católica oficial. O direito de nomear-se comunidade, de existir como coletividade é dado, assim, na contradição como o que o colonizador e os discursos dominantes permitem. Há assim uma decalagem entre as práticas da existência e o permitir se categorizar conforme os modos de funcionamento das categorias das ideologias dominantes. Ao outro é dado o poder e a autoridade de dizer quem somos conforme suas próprias categorias.

Cerqua (1980) descreve que, nas diversas localidades onde implantaram igrejas católicas, as moradias foram concentrando-se em volta das igrejas após a sua implantação. Já no Macurany isso não aconteceu, o que nos indica um modo de resistência à configuração imposta pela discursividade cristã católica, que organiza os espaços e as temporalidades em torno do templo. Os moradores permaneceram onde estavam, às margens dos igarapés, das cabeceiras e do lago do Macurany, assim como à margem do rio Parananema. A igreja em homenagem à Santa Luzia foi construída à margem da estrada do Macurany (que liga esta localidade à cidade de Parintins), num terreno doado à diocese de Parintins, numa posição central no espaço geográfico da comunidade, fora da margem do rio, diferente do que tradicionalmente acontece na maioria das comunidades amazônicas. Ao lado dela, no mesmo terreno, construíram um campo de futebol e ao lado deste, em outro terreno, doado à prefeitura, foi construída a Escola Municipal Santa Luzia do Macurany, em 1982 (LIMA DA SILVA, 2013). Lima da Silva (op. cit., 2018) analisa as disputas de sentidos em torno do termo comunidade na Amazônia, mas podemos destacar que, a partir de sua construção, a igreja passou a ser o local de encontro para as atividades religiosas e para tratar de assuntos de interesses políticos e sociais. Assim, nesse contexto, a partir de uma perspectiva religiosa católica, a noção de "comunidade" foi introduzida e assumida como significação na localidade.

Nas últimas duas décadas, devido ao acelerado processo de crescimento urbano da cidade, Parintins e especificamente a comunidade do Macurany têm sofrido fortes impactos sociais e ambientais. Assim, em nome de um suposto desenvolvimento e progresso, houve muito desmatamento, caça e pesca predatórias na região, tornando-a mais uma localidade atravessada pelas contradições das formações sociais amazônidas. Os limites entre a comunidade rural, considerada Área de Proteção Ambiental (APA), e a área de expansão urbana, descritos na lei orgânica e no plano diretor do município de Parintins, são confusos, pois nestas leis não há definições precisas quanto a esses limites, uma vez que a referida APA 
necessita de regulamentação por lei específica. Essa confusão possibilitou a implantação, na área da comunidade, de loteamentos e conjuntos habitacionais, assim como favoreceu o aumento da especulação imobiliária na localidade, isto é, quem tem dinheiro aproveita para lucrar comprando e vendendo terras. Por outro lado, os moradores (principalmente os mais antigos) sentiram o impacto da grande mudança no modo de vida, passando a conviver com novos vizinhos (estranhos ao modo de vida que levavam), com medo da criminalidade, que aumentou, com a escassez de peixes nos lagos e de produtos que eram extraídos nas matas das proximidades. Na medida do possível, resistem, com a criação de associações de moradores, para lutarem por preservação ambiental e sustentarem outras manifestações tradicionais. Remetemos o leitor para a análise feita por Lima da Silva (2018), em que exploramos e analisamos, a partir de entrevistas e documentos, nessas condições de produção, a disputa de sentidos entre as discursividades do domínio religioso, sobretudo cristã católica, do domínio político e ambientalista, do domínio jurídico e capitalista, do domínio rural-ribeirinho, da modernidade e do progresso, do domínio desenvolvimentista-capitalista. Essas são discursividades recorrentes instaladas e convocadas com a colonização na Amazônia. Logo, essas problemáticas locais, brevemente expostas, revelam a presença de diferentes interesses e grupos sociais em disputa nesse contexto, diferentes forças ideológicas e relações de poder, em desigualdade e contradição, determinando as práticas sociais que constituem o processo histórico envolvendo a comunidade do Macurany.

\section{Os efeitos trágicos e catastróficos de certas discursividades na Amazônia}

Como vimos, são múltiplas formas de violência que desabam nesses sujeitos: simbólica, moral, política, social, econômica e física. Essa disputa sempre assume um aspecto fatalista e determinista para os oprimidos, o que se explica justamente pelo processo histórico que a sustenta e que se reproduz por processos discursivos: os diferentes modos e materialidades historicizados da violência nos fazem aceitar que há pouco o que se fazer, e de nada adianta reagir, a não ser resignar-se.

Por isso, num contexto mais amplo, a comunidade do Macurany pode ser contada entre as diversas comunidades ribeirinhas que compõem a Amazônia e, como tal, inserida em condições históricas também mais amplas, das quais todas fazem parte.

Em Fraxe, Witkoski e Pereira (2007, p. 182), um estudo sobre comunidades ribeirinhas das margens do rio Solimões, é possível encontrar referência a uma "conjuntura econômica, social e política, construída e marcada historicamente por uma deliberada ausência de políticas 
públicas de inclusão social", na qual famílias ribeirinhas sofrem dificuldades decorrentes da escassez de peixes, dos conflitos de pesca, do analfabetismo, da baixa qualidade de seus produtos etc. Como comentamos acima, Martins de Souza (2000) mostrou como se atualizam os processos discursivos que corroboram com a exclusão dos povos amazônidas, e mais ainda dos povos indígenas que ocupam milenarmente a região, através das políticas públicas e culturais no Brasil. Como podemos depreender daí, a prática simbólica constitui a prática social e política assim como é por ela constituída. Na linguagem, as diferentes forças ideológicas em jogo no processo sócio-histórico se materializam em forma de discursos, em formações discursivas e processos discursivos.

De fato, é preciso recuperar como nossas formações sociais se relacionam com as discursividades cuja constituição remonta aos tempos coloniais do Brasil e da Amazônia. A forma como as comunidades ribeirinhas são tratadas hoje pelo Estado brasileiro, nos canais e produtos midiáticos, tem aí seu princípio e seu fundamento histórico e discursivo, um processo histórico que se desenvolveu tendo a linguagem como base que sustentou e sustenta diversos fatores de desigualdade social, pois é através da produção simbólica que se materializam os diferentes posicionamentos ideológicos, posições de sujeito, fazendo assim sentido o favorecimento de uns em detrimento de outros, a expressão e a comunicação de uns e o silenciamento de outros, a vida, a morte e a extinção de brasileiros e de nossas riquezas culturais, econômicas e naturais. Por isso, a ausência de políticas públicas são efeitos da e promovem a perpetuação de tais processos discursivos.

Ainda sobre as formações sociais amazônidas e a noção de comunidade, o antropólogo americano Wagley (1988) descreve:

\footnotetext{
Por toda parte as pessoas vivem em comunidade - em bandos, em aldeias, em núcleos agrícolas, nas pequenas e nas grandes cidades. Nas comunidades existem relações humanas de indivíduo para indivíduo, e nelas, todos os dias, as pessoas estão sujeitas aos preceitos de sua cultura. É nas suas comunidades que os habitantes de uma região ganham a vida, educam os filhos, levam uma vida familiar, agrupam-se em associações, adoram seus deuses, têm suas superstições e seus tabus e são movidos pelos valores e incentivos de suas determinadas culturas. Na comunidade, a economia, a religião, a política e outros aspectos de uma cultura parecem integrados e formam parte de um sistema geral de cultura, tal como o são na realidade. Todas as comunidades de uma área compartilham a herança cultural da região e cada uma delas é uma manifestação local das possíveis interpretações de padrões e instituições regionais (WAGLEY, 1988, p. 44).
}

Esta visão antropológica de Wagley sobre comunidade possibilita pensá-la como parte de um todo integrado (de uma região ou país, por exemplo), sendo que esta parte pode refletir traços culturais de um todo ao mesmo tempo em que possui suas particularidades. Por isso, a 
compreensão de uma comunidade é melhor quando se tem a visão geral da região onde ela está inserida, no caso da comunidade do Macurany, por exemplo, da Região Amazônica. Essa integração parece bem articulada, sem conflitos e contradições que sobressaiam, o que faz dessa representação, uma idealização do que de fato acontece.

Relacionando-se e disputando com essa interpretação, Bauman (2001) recorre ao mito grego de Tântalo e ao de Adão e Eva para outra noção de comunidade. Para ele, aquela comunidade antiga, que produz uma sensação boa, de segurança, um lugar pequeno onde não há perigo, onde todos são amigos, ingênuos e inocentes, existe somente em sonho, pois a moderna sociedade rompe os muros dessa comunidade, na medida em que, como na situação de Tântalo e de Adão e Eva, os membros dela adquirem e compartilham um conhecimento a que não deveriam ter acesso:

\begin{abstract}
A distância, outrora a mais formidável das defesas da comunidade, perdeu muito de sua significação. O golpe mortal na 'naturalidade' do entendimento comunitário foi desferido, porém, pelo advento da informática: a emancipação do fluxo de informação proveniente do transporte de corpos. A partir do momento em que a informação passa a viajar independente de seus portadores, e numa velocidade muito além da capacidade dos meios mais avançados de transporte (como no tipo de sociedade que todos habitamos nos dias de hoje), a fronteira entre o 'dentro' e o 'fora' não pode mais ser estabelecida e muito menos mantida (BAUMAN, 2001, p.18).
\end{abstract}

Considerando o pensamento de Bauman exposto acima, entendemos que, para ele, comunidade foi muitas vezes pensada como um paraíso, um lugar procurado pelos homens, mas não encontrado, porque neste mundo, cada vez mais globalizado, a informação invade todos os lugares e a comunidade, antes pensada como um lugar harmônico e fechado, não resiste a isso.

Na Amazônia, a distância entre grandes centros urbanos e comunidades ribeirinhas, como o Macurany, foi paulatinamente diminuída não só pela chegada de energia elétrica e de recursos tecnológicos, como o acesso ao rádio e à $\mathrm{TV}$, mas também pela inovação tecnológica da capacidade dos motores de embarcações, pela construção de aeroporto em Parintins, pelo investimento maciço da Coca-Cola no festival de Parintins, junto com as secretarias estadual e municipal de cultura, que o transformou, como já apontamos, num evento internacional, a partir do começo dos anos 90, e, por fim, como também enumeramos acima, pelos processos políticos e econômicos na busca e comercialização de recursos naturais na Amazônia.

De todo jeito, a significação da distância na Amazônia, diferente do que aponta Bauman (2001), ainda se fortalece pelos matizes que as discursividades da colonização construíram: ao invadirem os espaços, ao dizimarem nações indígenas inteiras, se fortalece o enunciado ou proposição de base "índio não tem alma, logo, índio não deve existir", como núcleo interno consistente, resistente e encapsulado, de uma formação discursiva cujas materializações, com 
sua constitutiva, concreta e violenta força simbólica, analisamos em diferentes trabalhos (MARTINS DE SOUZA, 2000, 2008, 2013, 2019; MARTINS DE SOUZA \& FREIRE, 2004; LIMA DA SILVA, 2018). É sempre necessário retomar o registro pelo vigário de Belém, Manoel Teixeira, no momento de sua morte, em 1654, confessando como as diversas e populosas cidades amazônicas, dos diferentes povos que aqui habitavam, foram sendo destruídas:

(...) se exercitaram sempre grandes injustiças e crueldades extraordinárias contra os índios, queimando-lhes suas povoações, matando muitos milhares deles, sem piedade, nem causa, e trazendo muitos cativos, sem mais razão, nem justiça, que ser maior o nosso poder.

(...) no espaço de trinta e dois anos(...) são extintos a trabalho e a ferro, segundo conta dos que ouviram, mais de dois milhões de índios de mais de quatrocentas aldeias, ou para melhor dizer cidades muito populosas...e certifico que os moradores deste Estado se tem servido desde o princípio de grandíssimo número de índios a título de escravos(...) trazendo-os despidos, assim homens como mulheres, com grande indecência e dando-lhes muito mal de comer e chamando-lhes nomes muito feios e afrontosos, de que eles muito se sentem... (apud BESSA FREIRE et al, 1991, anexo).

Se, em apenas 32 anos da empresa colonial na região, cidades e povos inteiros foram totalmente dizimados, se houve o genocídio de mais de 2 milhões de indígenas, isso se perpetua na América Latina, como comprovam os noticiários. No cotidiano amazônida estão as marcas simbólicas e reais do fato de que sequer existíamos como seres humanos no olhar do outro europeu ou dos poderosos. Se o outro nos constitui e constitui nosso desejo, o que ele enxerga ou deixa de enxergar estende e finca o seu poder e o seu domínio na constituição dos sujeitos pela ideologia e pelo inconsciente (PÊCHEUX, 1988; ORLANDI, 1990, 1991). Dessa forma, contraditoriamente o não existir nos constitui com a evidência e a força do estar vivo. A Amazônia vive essa contradição que a coloca nesse momento como um dos lugares mais importantes do planeta, mas simbolicamente carrega a memória do apagamento, do silenciamento, da negação, da falta de acesso a políticas públicas e a expressão de si. Ainda não nos falamos, não temos voz, não somos publicados ou não nos permitem nos expressarmos nos diferentes produtos culturais. Qualquer artista, intelectual ou personalidade amazônida ainda vivencia essa violência simbólica. Mais ainda os sujeitos indígenas, os sujeitos ribeirinhos, e os caboclos. Somos constituídos no conflito e na contradição entre o econômico, o religioso, o ancestral, o colonizador e o contemporâneo. As disputas entre o avanço da urbanização e o modo de vida milenar amazônico, com sua espacialidade e temporalidade singulares, afetam os moradores antigos do Macurany e precisam ser melhor mapeadas. Acreditamos que a transformação e a recuperação de um modo de vida mais digno virão através da exposição, análise e aprofundamento, pela arte, pela educação, por pesquisas e por produtos midiáticos, dos problemas e dos efeitos catastróficos dessa violência simbólica, moral, política, social, 
econômica e física, causados por essas discursividades. Se pela linguagem elas se perpetuam, é pela linguagem, pelos sentidos e pela autoria, fazendo dos corpos amazônicos, cadeias significantes da resistência, que elas podem ser derrotadas.

\section{REFERÊNCIAS}

BATISTA, Djalma. O complexo da Amazônia: análise do processo de desenvolvimento. $2^{\circ}$ ed. Manaus: Editora Valer, Edua e Inpa, 2007.

BAUMAN, Zygmunt. Comunidade: a busca por segurança no mundo atual. Tradução de Plínio Dentzen. Rio de Janeiro. Jorge Zahar, 2001.

BESSA FREIRE, José Ribamar et al. A Amazônia Colonial (1616-1798). $4^{\mathrm{a}}$ ed. Manaus: Ed. Metro Cúbico, 1991.

BITTENCOURT, Antônio C. R. Memória do Município de Parintins. Manaós: Livraria Palam Roval, 1924.

BUTEL, Larice et al. História e memória política do município de Parintins de 1947 a 1963. v. 1. Parintins: Câmara Municipal de Parintins, 2011.

CERQUA, Arcângelo. Clarões de Fé no Médio Amazonas. Manaus, AM. Imprensa Oficial do Estado do Amazonas, 1980.

CORREA DA SILVA, Marilene. O Paiz das Amazonas. Dissertação de mestrado. PUC SP, 1989.

Desenvolvimento Sustentável e Urbanização: do Conhecimento à Ação, documento da ALCUE (diálogo da América Latina, Caribe e União Européia sobre Ciência e Tecnologia), Oaxaca, México, 18/11/2001.

DIRETÓRIO. fac-símile publicado no Boletim de pesquisa da CEDEAM, vol. 3, no. 4, Manaus: FUA, 1984.

FRAXE, Terezinha; WITKOSKI, Antônio Carlos; PEREIRA, Henrique dos Santos. Comunidades ribeirinhas amazônicas: memória, ethos e identidade. Manaus: EDUA, 2007.

GALVÃO, E. Encontro de sociedades. Rio de Janeiro, Paz e Terra, 1955.

HALL, Stuart. A identidade cultural na pós-modernidade. Trad. Tomaz Tadeu da Silva. 3 ed. Rio de Janeiro: DP\&A Editora, 1999.

LAGAZZI, Suzy. A Materialidade Significante em Análise. In: A Análise do Discurso e suas Interfaces. Leda Verdiani Tfouni, Dionéia Motta Monte-Serrat e Paula Chiaretti (org.) São Carlos: Pedro \& João Editores, 2011.

LIMA DA SILVA, Almiro. História da Comunidade do Macurany: as problemáticas sociais decorrentes do crescimento da cidade de Parintins - AM. (Relatório de pesquisa apresentado ao Programa de Apoio à Iniciação Científica - PAIC) do CESP/UEA. AM: Parintins, 2013.

Almiro. A memória e presente da comunidade do Macurany, em

Parintins/AM: análise discursiva. Dissertação (Mestrado em Letras / Estudos da Linguagem). Universidade Federal do Amazonas. Manaus, 2018.

MARTINS DE SOUZA, Luiz Carlos. A Identidade dos Ribeirinhos do rio Acajatuba: uma perspectiva discursiva. Dissertação de mestrado: UFAM, 2000.

MARTINS DE SOUZA, Luiz Carlos. O norte apagado: o silenciamento amazônico. In: MITTMANN, Solange; GRIGOLETTO, Evandra; CAZARIN, Ercília Ana. (Org.). Práticas Discursivas e Identitárias: sujeito e língua. Porto Alegre: Nova Prova, 2008.

MARTINS DE SOUZA, Luiz Carlos. Cartas para quem?: o funcionamento discursivo da "falta" no filme Central do Brasil. Tese (Doutorado - Universidade Estadual de Campinas, Instituto de Estudos da Linguagem). Campinas: 2012. $251 \mathrm{f}$. 
MARTINS DE SOUZA, Luiz Carlos. A selva na selva: uma experiência com o doctv. In DAVINO, Glaucia Davino e BELLICIERI, Fernanda. Histórias de roteiristas: Roteiros, dispositivo audiovisual. São Paulo: Universidade Presbiteriana Mackenzie, 2013. 475 p.

MARTINS DE SOUZA, Luiz Carlos. Memes e identidades amazônicas: Narciso acha feio o que é espelho. Policromias, Rio de Janeiro, v. 4, n. 2, p. 189-212, Dez, 2019.

MARTINS DE SOUZA, Luiz Carlos; FREIRE, Paulo Cezar. A Selva na Selva, DOCTV. Fundação Padre Anchieta e Ministério da Cultura, Brasil, DVD. 54min. 2004.

OLIVEIRA, Liliane Costa de. Vida religiosa ribeirinha: Um estudo sobre a Igreja Católica e Evangélica no Amazonas. Dissertação (Mestrado em Sociologia). Universidade Federal do Amazonas, 2012.

ORLANDI, Eni Puccinelli. Terra à Vista. São Paulo: Cortez/UNICAMP, 1990.

Eni Puccinelli (org.). Discurso Indígena: a materialidade da Língua e o movimento da identidade. Campinas: UNICAMP, (1991).

, Eni Puccinelli. Análise de discurso: princípios e procedimentos. Campinas: Pontes, 1999.

PÊCHEUX, Michel. Semântica e discurso: uma crítica à afirmação do óbvio. Campinas: Editora da Unicamp, 1988.

REIS, Arthur Ferreira Cézar. As origens de Parintins. Manaus, AM: Governo do Estado do Amazonas, 1967.

RODRIGUES DE ARAUJO, Karen Dominique. O discurso sobre a sexualidade feminina: subjetividades e identidades em construção. Dissertação (Letras e Artes) - Universidade Estadual do Amazonas. Manaus, 2018.

SAUNIER, Tonzinho. Parintins: Memória dos Acontecimentos Históricos. - Manaus: Editora Valer / Governo do Estado do Amazonas, 2003.

SILVA, Charlene Maria Muniz da. Mocambo, Caburi, Vila Amazônia no município de Parintins: Múltiplas faces do urbano e do rural. Dissertação (Mestrado em Geografia). Universidade do Estado do Amazonas, 2009.

SOUZA, Nilciana Dinely de. O processo de urbanização da cidade de Parintins (AM): evolução e transformação. Tese (Doutorado em Geografia). Universidade de São Paulo, Faculdade de Filosofia, Letras e Ciências Humanas (FFLCH) - SP: [s.n], 2013.

TOCANTINS, Leandro. $O$ rio comanda a vida: uma interpretação da Amazônia. $-7^{\circ}$ ed. rev. e aum. - Rio de Janeiro: J. Olympio: Manaus: SUFRAMA, 1983.

WAGLEY, C. Uma comunidade amazônica: estudo do homem nos trópicos (1956). São Paulo: Editora Nacional, 1988. 